\title{
The Influence of Fan Economic Marketing on Enterprises in the Current Market
}

\author{
Jingyi Zhang
}

\begin{abstract}
Nanjing Foreign Language School Xianlin Branch
\end{abstract}
3176153271@qq.com

\begin{abstract}
With the progress of the times, the Internet is becoming more and more developed. All kinds of media emerge in endlessly. Gradually, fans also begin to appear as a group with great commercial value"Words such as "carrying goods", "endorsement ambassador" and "XXX recommendation" began to become the key to brand traffic and sales. In the era of fan economy, the economic model with idol as the core has become popular. The innovative and developed marketing means has also become an important stroke affecting enterprises. The research theme of this time is what impact the marketing means of fan economy has on enterprises and even society in the domestic market. For example, it plays a vital role in the change of marketing means of enterprises and plays an innovative role in the sales channel of the market.
\end{abstract}

Keywords: Fan economic marketing means domestic market, new media, Chinese marketing, Enterprise level.

\section{INTRODUCTION}

"As an emerging economic model in the Internet era, it has the dynamic characteristics of continuous change[4]." All kinds of marketing models are used by major companies and brands. By means of taking goods online and jointly signing with stars, enterprises gain great benefits. Therefore, enterprises begin to want to innovate models, occupy the market, create exclusive features for brands, and increase more traffic. People began to have great interest in the concept of fans and fan economy. What kind of new economy can attack such a large market and attract so many customers. This economic model and its impact on enterprise and social development. What impact does fan economy have on enterprises? What are the new marketing methods? What effect does it have on society? These are all questions people need to think about. At present, through the review of literature and the analysis of specific examples, it is concluded that the fan economy contains huge business opportunities and development prospects. If it is properly used, it can further promote economic development with the help of the Internet.

\section{FAN ECONOMY}

Fan economy, as the name suggests, is the economic benefits brought by fans. Use fans as a resource to create operational benefits. It itself is to build the relationship with fans and people who are concerned, that is, contemporary stars, online celebrities or celebrities who have the right to speak or influence in some professional fields. Zhang Qiang, the author of "great power of fans", once said that the fan economy is to take emotional capital as the core and fan community as the marketing means to add value to emotional capital. The understanding of fan economy in the domestic market is a new economic model generated by the development of fan culture. "With the rise of microblog, Taobao and wechat, the development of fan economy is becoming more and more diversified[3]." Diversification means entering new markets to increase the probability of enterprise survival[5].Fan economy takes consumers as the protagonist and consumers dominate the marketing means. Starting from consumers' emotions, enterprises use their strength to achieve the purpose of adding emotional capital to brands and idols. With the development of the Internet, more and more platforms appear, which provides a lot of convenience for the development of fan economy. Especially in China, a country with such a large 
population, fan economy is a big cake coveted by many companies. Although some fans, just students or minors, have no spending power, the vast majority of fans will vote for their idols, make lists, grab tickets to concerts and so on. This is the idol effect. It is also the benefit that fans pay for their emotions and bring to the industries involved. Generally speaking, idol effect is that a large number of fans pursue a product or brand because of the endorsement of idols, or "the same style of idols", which has never brought great benefits to businesses. If people grasp this business opportunity, the brand can increase its exposure, expand the consumer group for the product, and strengthen customer loyalty and viscous consumption of the product.

\section{THE MARKETING MEANS ADOPTED BY ENTERPRISES TO UTILIZE FAN ECONOMY}

Professor Asher said that the reason for the existence of the company is the division of labor. The company has become the result of the increasingly complex division of labor. The marketing department of the company is a division of labor. "This division of labor means that through different means of economic competition, you can increase the competitiveness of our own brands and cannot be replicated[6]."In the era of fan economy, the spokesmen ambassadors, brand friendly partners and image spokesmen of major brands are the marketing means chosen by enterprises for their products. Huawei is a very famous mobile phone brand. It has many series of brands, and its spokesmen in the world are many international stars. After the first taste of sweetness, Huawei invited Zhang Hanyu, the first domestic star spokesperson, as the spokesperson of Huawei mate 9, Mate9 sold more than 8.5 million units, and then Huawei hired a series of domestic famous stars as spokesmen for its products. During this period, it launched activities such as buying mobile phones and sending posters, and launching "you and Aidou use the same mobile phone" to maximize the benefits to meet the needs of consumers and fans. Posters can be seen everywhere on the street, advertisements pushed by tens of millions of stars on microblog, large screen projection on Subway.Not only greatly increased the public exposure of mobile phones, but also pushed Huawei to the peak of domestic mobile phones. This has not only laid a solid foundation for Huawei's customer traffic, but also given Huawei more development opportunities. For example, the Huawei computer Huawei tablet launched in the later stage has also reaped good sales. This marketing method is undoubtedly successful. More and more brands, in order to keep up with the trend, began to invite stars to endorse and launch co-branded products. However, it is undeniable that the benefits of fan economy to enterprises are unstable. In recent years, many brand spokesmen have overturned frequently. For example, negative news such as "a actress is involved in the surrogacy storm" and "a contemporary top class adultery minors" will greatly affect and lose relevant endorsements and businesses. These brands are often eager to be Guan Gong to get rid of the relationship. At that time, the fan economy may be a negative support.

\section{THE IMPACT OF FAN ECONOMY ON ENTERPRISES}

\subsection{Definition of the enterprise}

Enterprises include a unique and difficult to trade portfolio of assets and capabilities. It also requires unique and difficult to replicate assets, which can be used to continuously create, expand, upgrade and protect the relevant assets of the enterprise. As a manager of an enterprise, the manager needs to (1) perceive and shape opportunities, (2) seize opportunities, and (3) maintain competitiveness by enhancing, combining, protecting and, if necessary, reallocating the intangible and tangible assets of the enterprise. The traffic brought by stars and online celebrity endorsements and the unique brand image are intangible assets of the enterprise[4]"

\section{2 positive of the fans economy}

The power of fans is huge. Many stars also want to be popular. They spend a lot on establishing a good public relations image, such as doing public welfare and donating money to help the poor. Under their leadership, fans also automatically formed groups to do public welfare. Over the years, the public welfare has been made by the fans, and the materials donated by the volunteers, even the primary school donated, and the roads built are beyond count. Especially, COVID-19 is faced with this large-scale public health emergency. people can see that the funds donated by the big stars and the stars will actively donate materials, take the lead in the isolation of the home, and guide the public to wear masks. Listen to the country... Wait. Not only that, but in this case, there was a nurse in COVID-19 who was in the front line of epidemic prevention. She published her own daily fight against micro-blog on the micro-blog epidemic. After seeing the star she love, she arranged the meeting in the next program. The girl is undoubtedly happy and lucky. Later, it was reported that she was a diligent medical staff. Although she was a post-90s, she never lowered her head in front of the epidemic and rushed to the front line spontaneously. It is because of her long efforts and her excellence that she met her idol. This is glorious. This is great spiritual comfort and support. In terms of economy or spirit, fan economy is a great contribution to society. Virtually, it also brings great benefits to the related industries. In 2021, due to natural disasters, heavy rain and serious floods in Henan, the domestic brand Hongxing Erke made a wild donation of 50 million, equivalent to its net 
profit for several years. As soon as this move came out, people all over the country were fans of Hongxing Erke at this time. Without organization, they spent wild consumption in Hongxing Erke's live broadcasting room and offline stores, which made Hongxing Erke's daily income exceed tens of millions and directly saved an endangered and bankrupt enterprise. How huge is this power. This is the fan economy. In 2020, a well-known contemporary top class spoke for a food under Jingdong: open a small stove. According to the research report released by Puyin international, the revenue of unified small stoves exceeded 170 million in the first half of this year (many e-commerce platforms have been in a tight inventory), an increase of 15 times year-on-year, accounting for $3 \%$ of the convenience food business, and became the first product in the list in January 2020. This is undoubtedly a leap forward increase, which makes more enterprises see the power of fan economy. At the same time, it also proves the cargo carrying capacity of a well-known domestic star. He (generally refers to a star with high cargo carrying capacity) also proves their strength to capital. It is not difficult to see that the fan economy is very different from the traditional economy in the past. Having a sharp and vicious vision, being able to grasp the market and resources, constantly expanding the explosion point of marketing and making topics for their products by using the resources of the carrier are the key to success.

\section{3 negative impact of fans economy}

However, it is not the fan economy that is profit without harm. If you just blindly use fan resources, but ignore making products with your heart, do not invest enough money and have time to develop products, even if the market competitiveness of the product itself is not enough, even with the bonus of fan economy, it will be eliminated by the market. "For example, L'Oreal cosmetics has frequently changed its spokesperson and forcibly injected the enterprise value, potentially losing many customers[3]. At the same time, it also caused disgust among fans."Excessive consumption of fans leads the fan group to a morbid consumption. There will be a talent show in which fans vote for their idols and buy a lot of milk, but they pour all the milk afterwards. Such extravagance and waste will finally arouse social condemnation. The company should pay more attention to the fit between the product and the spokesperson, let consumers focus on the product itself, tap the potential real demand of customers for the product, make good products and increase customer stickiness and loyalty. The key to success is to brand goods, further improve operation standards and build a complete production and supply chain. "The state should also ensure fair transactions and friendly competition among enterprises[2]. Formulate relevant measures. Trading rules specify who can trade with whom and under what conditions. Rules on transportation, billing, insurance, currency exchange and contract execution must be specified. These rules are particularly important in the whole society, and the state is very important to formulate and implement the rules. The most important benefit of fan economy to enterprises is to increase product exposure, quickly cash in traffic, greatly improve product sales, and form a certain degree of customer loyalty. "The biggest disadvantage is its huge traffic exposure. Once the relevant products or related events are exposed, it will also be a fatal blow to the enterprise ( The fan economy has a vital impact on the enterprise. It can lead the enterprise to create unique products and strive for huge benefits. In China, the advantages of fan economy outweigh the disadvantages. As long as the company grasps the fan economy, it will undoubtedly occupy part of the territory in the domestic market. The future development of fan economy may be more inclined to contribute to the society as a whole, especially advocating public welfare and so on. The state will also advocate appropriate consumption and so on."Brands should pay more attention to the combination of products and traffic, have a thoughtful and perfect service chain, lock their loyal customers and introduce more passenger flow[1]."

\section{CONCLUSION}

The advantage of fan economy is that it can greatly improve the exposure of products, attract many high-quality customers and earn huge commercial benefits for the company by mastering the flow and a large number of performance. The disadvantage is that this economic model is unstable, and improper operation will seriously damage the company's image. Fan economy can be optimized. It needs to be controlled within a range, which can not only meet the needs of customers, but also maximize the interests of the company.

\section{REFERENCES}

[1]. Gongna.(2018).Marketing model of online fans from the perspective of communication. Issue 04.

[2]. Zhaili.(2021). Research on fan economy of webcast with goods. Issue 13.

[3] Zhanghubo.(2021).Analysis of enterprise marketing strategy from the perspective on fan economy.Issue 22

[4] DAVID J. (2007). TEECE. Wiley Inter Science

[5] Neil F.Markets as politics American Sociological Review, Volume 61,Issue4.56-673

[6] R.H C.(1937). The Nature of the Firm. 